(C) The Authors 2016. This is an Open Access article, distributed under the terms of the Creative Commons Attribution licence (http://creativecommons.org/licenses/by/4.0/), which permits unrestricted re-use, distribution, and reproduction in any medium, provided the original work is properly cited.

\title{
5-Hydroxyvitamin D concentration in paediatric cancer patients from Scotland: a prospective cohort study
}

\author{
Raquel Revuelta Iniesta ${ }^{1,2 *}$, Ilenia Paciarotti ${ }^{1,2}$, Isobel Davidson ${ }^{1}$, Jane M. McKenzie ${ }^{1}$, Celia Brand ${ }^{3}$, \\ Richard F. M. Chin ${ }^{2,3,4}$, Mark F. H. Brougham ${ }^{5}$ and David C. Wilson ${ }^{2,6}$ \\ ${ }^{1}$ Dietetics, Nutrition and Biological Health Sciences, Queen Margaret University, Edinburgh, EH21 6UU, UK \\ ${ }^{2}$ Child Life and Health, University of Edinburgh, Edinburgh, EHO $1 U \mathrm{~W}, \mathrm{UK}$ \\ ${ }^{3}$ Department of Paediatric Neuroscience, Royal Hospital for Sick Children, Edinburgh, EHO 1LF, UK \\ ${ }^{4}$ Muir Maxwell Epilepsy Centre, University of Edinburgh, Edinburgh, EH9 $1 U \mathrm{~W}, \mathrm{UK}$ \\ ${ }^{5}$ Department of Haematology and Oncology, Royal Hospital for Sick Children, Edinburgh, EH9 1LF, UK \\ ${ }^{6}$ Department of Paediatric Gastroenterology and Nutrition, Royal Hospital for Sick Children, Edinburgh, EH9 1LF, UK
}

(Submitted 15 February 2016 - Final revision received 21 October 2016 - Accepted 26 October 2016 - First published online 15 December 2016)

\section{Abstract}

Children with cancer are potentially at a high risk of plasma 25-hydroxyvitamin D (25(OH)D) inadequacy, and despite UK vitamin D supplementation guidelines their implementation remains inconsistent. Thus, we aimed to investigate $25(\mathrm{OH}) \mathrm{D}$ concentration and factors contributing to $25(\mathrm{OH}) \mathrm{D}$ inadequacy in paediatric cancer patients. A prospective cohort study of Scottish children aged $<18$ years diagnosed with, and treated for, cancer (patients) between August 2010 and January 2014 was performed, with control data from Scottish healthy children (controls). Clinical and nutritional data were collected at defined periods up to 24 months. 25(OH)D status was defined by the Royal College of Paediatrics and Child Health as inadequacy $(<50 \mathrm{nmol} / \mathrm{l}$ : deficiency $(<25 \mathrm{nmol} / \mathrm{l})$, insufficiency $(25-50 \mathrm{nmol} / \mathrm{l}))$, sufficiency $(51-75 \mathrm{nmol} / \mathrm{l})$ and optimal (>75 nmol/1). In all, eighty-two patients (median age 3.9, interquartile ranges (IQR) $1.9-8.8 ; 56 \%$ males) and thirty-five controls (median age $6 \cdot 2$, IQR $4 \cdot 8-9 \cdot 1 ; 49 \%$ males) were recruited. $25(\mathrm{OH}) \mathrm{D}$ inadequacy was highly prevalent in the controls $(63 \% ; 22 / 35)$ and in the patients (64\%; 42/65) at both baseline and during treatment (33-50\%). Non-supplemented children had the highest prevalence of 25(OH)D inadequacy at every stage with $25(\mathrm{OH}) \mathrm{D}$ median ranging from $32 \cdot 0$ (IQR 21.0-46.5) to $45 \cdot 0(28 \cdot 0-64.5) \mathrm{nmol} / \mathrm{l}$. Older age at baseline $(R-0 \cdot 46 ; P<0 \cdot 001)$, overnutrition (BMI $\geq 85$ th centile) at 3 months $(P=0.005$; relative risk $=3 \cdot 1)$ and not being supplemented at 6 months $(P=0.04$; relative risk $=4 \cdot 3)$ may have contributed to lower plasma $25(\mathrm{OH}) \mathrm{D}$. Paediatric cancer patients are not at a higher risk of $25(\mathrm{OH}) \mathrm{D}$ inadequacy than healthy children at diagnosis; however, prevalence of $25(\mathrm{OH}) \mathrm{D}$ inadequacy is still high and non-supplemented children have a higher risk. Appropriate monitoring and therapeutic supplementation should be implemented.

Key words: 25-Hydroxyvitamin D: Paediatrics: Cancer: Scotland

Plasma 25-hydroxyvitamin D (25(OH)D) inadequacy $(<50 \mathrm{nmol} / \mathrm{l}$; deficiency and insufficiency) is a recognised health problem ${ }^{(1)}$. Despite vitamin D supplementation guidelines ${ }^{(2,3)}$, their implementation remains inconsistent ${ }^{(4)}$ and $25(\mathrm{OH}) \mathrm{D}$ inadequacy in healthy children ranges from 14 to $49 \%$ worldwide ${ }^{(5)}$. A recent systematic review reported prevalence of plasma $25(\mathrm{OH}) \mathrm{D}$ deficiency and insufficiency of 41 and 59\%, respectively, in European paediatric cancer patients, higher than healthy children and paediatric cancer patients from North America (15 and 46\%) and the Middle East (24 and $51 \%)^{(6)}$.

Plasma $25(\mathrm{OH}) \mathrm{D}$ is primarily obtained from UVB sunlight through dermal synthesis, but it can also be obtained from the diet. However, few foods naturally contain vitamin $\mathrm{D}^{(7)}$, and in the UK fortification is rare ${ }^{(8)}$. In high-latitude countries, such as Scotland ${ }^{(8)}$, populations are at an increased risk of $25(\mathrm{OH}) \mathrm{D}$ inadequacy. Other factors contributing to $25(\mathrm{OH}) \mathrm{D}$ inadequacy in children have been attributed to skin pigmentation, obesity and age (infants and adolescents) ${ }^{(2,7)}$.

Children treated for cancer experience multiple side effects, which might affect plasma 25(OH)D. These include phototoxicity, which requires avoidance of direct sunlight, reduced dietary intake $^{(9)}$, hepatotoxicity and nephrotoxicity, which may interfere with the activation of $25(\mathrm{OH}) \mathrm{D}^{(10)} \cdot 25(\mathrm{OH}) \mathrm{D}$ inadequacy in children increases the risk of bone fractures, rickets and slow growth $^{(11)}$, with a subsequent increased risk of osteoporosis ${ }^{(12)}$. Most children and adolescents treated for cancer survive into adulthood $^{(13)}$, but they have an increased risk of developing the metabolic syndrome, cardiac complications and have a reduced peak bone mass ${ }^{(13)}$. Despite the importance of vitamin $\mathrm{D}$ to health, the high prevalence of $25(\mathrm{OH}) \mathrm{D}$ inadequacy in Europe

Abbreviations: 25(OH)D, 25-hydroxyvitamin D; IQR, interquartile ranges; PTH, parathyroid hormone

* Corresponding author: Dr Raquel Revuelta Iniesta, email rrevueltainiesta@qmu.ac.uk 
and the recent call for high-quality population-based longitudinal cohort studies, there are a few published studies in the UK, and none in Scotland, investigating plasma 25(OH)D concentration in paediatric cancer patients ${ }^{(6)}$. To address this clinical question, we aimed to investigate both plasma $25(\mathrm{OH}) \mathrm{D}$ and parathyroid hormone (PTH) concentrations of paediatric cancer patients at defined time points for 24 months; compare plasma $25(\mathrm{OH}) \mathrm{D}$ concentration of healthy children with a paediatric cancer cohort from Scotland; and explore possible factors (age, ethnicity, sex, seasonality, nutritional status, diagnosis, treatment and the use of nutritional support) contributing to plasma $25(\mathrm{OH}) \mathrm{D}$ inadequacy at baseline and at 3 and 6 months.

\section{Methods}

\section{Study design, population and timeline}

A prospective cohort study was conducted. Eligibility criteria were children aged $<18$ years, diagnosed with cancer (International Classification of Childhood Cancer, third edition; ICCC-3) ${ }^{(14)}$ or Langerhans cell histiocytosis between August 2010 and January 2014 and attending the South East Scotland regional centre $\left(56^{\circ} \mathrm{N}\right)$ for Haematology and Oncology at the Royal Hospital for Sick Children (RHSC), Edinburgh or Ninewells Hospital, Dundee; patients were recruited consecutively. We excluded children who were treated palliatively at any time. Children were monitored for a maximum period of 24 months and all measurements were obtained at baseline (newly diagnosed), 3, 6, 9 and 12 months and every 6 months thereafter. Factors contributing to plasma 25(OH)D inadequacy were only explored at baseline and at 3 and 6 months because of the reduced sample size at later stages.

Anonymised control data were obtained from the control subjects recruited within a case-control study of vitamin D in children with epilepsy carried out between July 2013 and March 2014 at RHSC. Controls were recruited over an overlapping time frame, similar representative seasons and regions as the cancer patients. Consecutive potentially eligible controls attending the RHSC Emergency Department (which serves SE Scotland) who were previously healthy, not in extremis nor had an existing chronic condition (and specifically no epilepsy or other seizure disorder) and who required blood samples to be taken as part of their clinical assessment (e.g. child with a fever) were invited to the epilepsy study. Participants to the epilepsy study along with their parents gave written informed consent and - where appropriate informed assent. Recruitment was completed when the target sample size for each season was achieved. Advice on vitamin D supplementation was not provided before sample collection. Ethical approval for secondary use of the anonymised control data for comparison with that of the cancer patients in this study, without the need for additional consent, was given by the South East Scotland Research Ethics Service. Control data were not matched for age, sex or BMI; however, samples were matched for synthesising (1 April-30 September) and non-synthesising periods (1 October-31 March) for comparative reasons.

\section{Demographics and clinical parameters}

Clinical data (diagnosis, treatment protocol and length of treatment) and demographic data (age, sex, ethnicity and socio-economic deprivation) were collected from medical notes. Treatment intensity was classified according to Kazak et $a l .{ }^{(15)}$. As a proxy marker for socio-economic deprivation of individuals, we used Standard Index of Multiple Deprivation ${ }^{(16)}$.

The paediatric cancer cohort was grouped according to the wider definition of solid tumours, haematological cancers, brain tumours and other associated diagnoses.

\section{Data collection}

Plasma 25(OH)D, PTH, Ca, phosphate and Mg concentrations were measured. Plasma 25(OH)D was analysed using liquid chromatography-tandem MS technique at the Royal Infirmary of Glasgow and PTH was analysed using the Immulite 2000 Intact PTH technique at the Royal Infirmary of Edinburgh. The immediate CV (\%) for the assays were $\leq 8.9$ and $5.7 \%$, respectively. $\mathrm{Ca}$, phosphate and $\mathrm{Mg}$ were analysed using the Abbott Architect c8000 at RHSC.

Plasma 25(OH)D concentration was classified as synthesising (1 April-30 September) and non-synthesising periods (1 October-31 March). Plasma 25(OH)D status was defined according to the Royal College of Paediatrics and Child Health $(\mathrm{RCPCH})^{(2)}$ as deficiency $(<25 \mathrm{nmol} / \mathrm{l})$, insufficiency (25-50 nmol/l), sufficiency $(51-75 \mathrm{nmol} / \mathrm{l})$, optimal ( $>75 \mathrm{nmol} / \mathrm{l})$. Plasma 25(OH)D inadequacy was used when 25(OH)D concentration was $<50 \mathrm{nmol} / \mathrm{l}$. Plasma $25(\mathrm{OH}) \mathrm{D}$ toxicity was defined as $>175 \mathrm{nmol} / 1$ (with associated symptoms) and the PTH reference as $1.7-7.5 \mathrm{pmol} / \mathrm{l}^{(17)}$.

Height (or length) and weight were measured using standard procedures. BMI centile was calculated and UK BMI growth centiles were used. Nutritional status was classified as underweight $(\mathrm{BMI} \leq 2 \cdot 3$ th centile), healthy weight $(\mathrm{BMI}>2 \cdot 3$ rd to $<85$ th centile) and overweight $(\mathrm{BMI} \geq 85 \text { th centile })^{(18)}$. Vitamin D intake was assessed using a $24 \mathrm{~h}$ multi-pass recall method ${ }^{(19)}$ to establish patterns of change in vitamin $\mathrm{D}$ throughout the study period. This was analysed in WinDiets ${ }^{\circledR}$ (Univation Ltd 2005) programme ${ }^{(20)}$. Any nutritional treatment and vitamin D supplementation was recorded. Nutritional treatment was prescribed according to subjective global assessment by the multi-disciplinary team and consisted of enteral \pm parenteral nutrition (macronutrient) and micronutrient (vitamin D according to UK RCPCH guidelines ${ }^{(2)}$ or multivitamins), and a combination of macronutrients and micronutrients.

This study was granted ethical approval from NHS Scotland (NHS REC 06-51104-52).

\section{Statistical analyses}

The Statistical Package for Social Science (version 19; IBM-SPSS for Windows Statistics) was used to analyse all data. Descriptive statistics were used to evaluate the prevalence of plasma $25(\mathrm{OH}) \mathrm{D}$ inadequacy. Comparisons between the paediatric cancer cohort and the healthy controls were performed using Mann-Whitney test; correlations between plasma $25(\mathrm{OH}) \mathrm{D}$ and the following variables - $\mathrm{Ca}$, PTH, BMI centile and age - were performed using Spearman's correlation. Univariate associations between demographic data and categorical variables were established by $\chi^{2}$ test. $P<0.05$ was considered statistically significant. We followed the 
STROBE guidelines for the presentation of our data ${ }^{(21)}$. No a priori sample size estimation was performed for this pilot study in a regional cohort of paediatric cancer patients.

\section{Results}

\section{Demographic and clinical characteristics}

In all, thirty-three of thirty-five healthy controls and sixty-five of eighty-two paediatric cancer patients had plasma 25(OH)D samples available at baseline (Fig. 1). Of the healthy controls, two (6\%) samples were never returned because of laboratory issues. Demographic and clinical characteristics of the population are presented in Tables 1 and 2. Sex, ethnicity and socio-economic status, as well as age at diagnosis, did not statistically differ between groups. BMI centiles were significantly lower in the paediatric cancer cohort. A total of twenty-four treatment protocols were used to treat the paediatric cancer cohort, the median time follow-up was 312 (interquartile ranges (IQR) 123.5-653.2) d and $22 \%$ ( $n$ 18) were classified as low risk, $37 \%$ ( $n$ 30) as medium risk and $41.5 \%(n 34)$ as high risk. The time between diagnosis and baseline measurements was $15 \cdot 5$ (IQR 10·0-25.0) d and between the start of cancer treatment and baseline measurements was 9.5 (IQR 6.0-19.5) d. All patients were receiving cancer treatment when plasma 25(OH)D samples were taken.

\section{Plasma 25-hydroxyvitamin D concentration}

At baseline, of the eighty-two paediatric cancer patients, seventeen (21\%) did not have plasma 25(OH)D available because of clinical reasons (Fig. 1), thirty-four ( $41 \%$ ) were obtained during the synthesising period and thirty-one (38\%) during the nonsynthesising period. There was no difference $(U(453) ; P=0 \cdot 3)$ between the synthesising (median 39.0, IQR 30.0-62.0) and non-synthesising period (median 36, IQR 16.0-61.0) in plasma $25(\mathrm{OH}) \mathrm{D}$ concentration in the cancer cohort at any time point, apart from the 3-month follow-up (Fig. 2). Of the thirty-five controls, nineteen $(54 \%)$ were obtained during the synthesising period and twelve $(34 \%)$ during the non-synthesising period. Plasma $25(\mathrm{OH}) \mathrm{D}(\mathrm{nmol} / \mathrm{l})$ statistically differed $(U(42 \cdot 5) ; P=0 \cdot 003)$ during

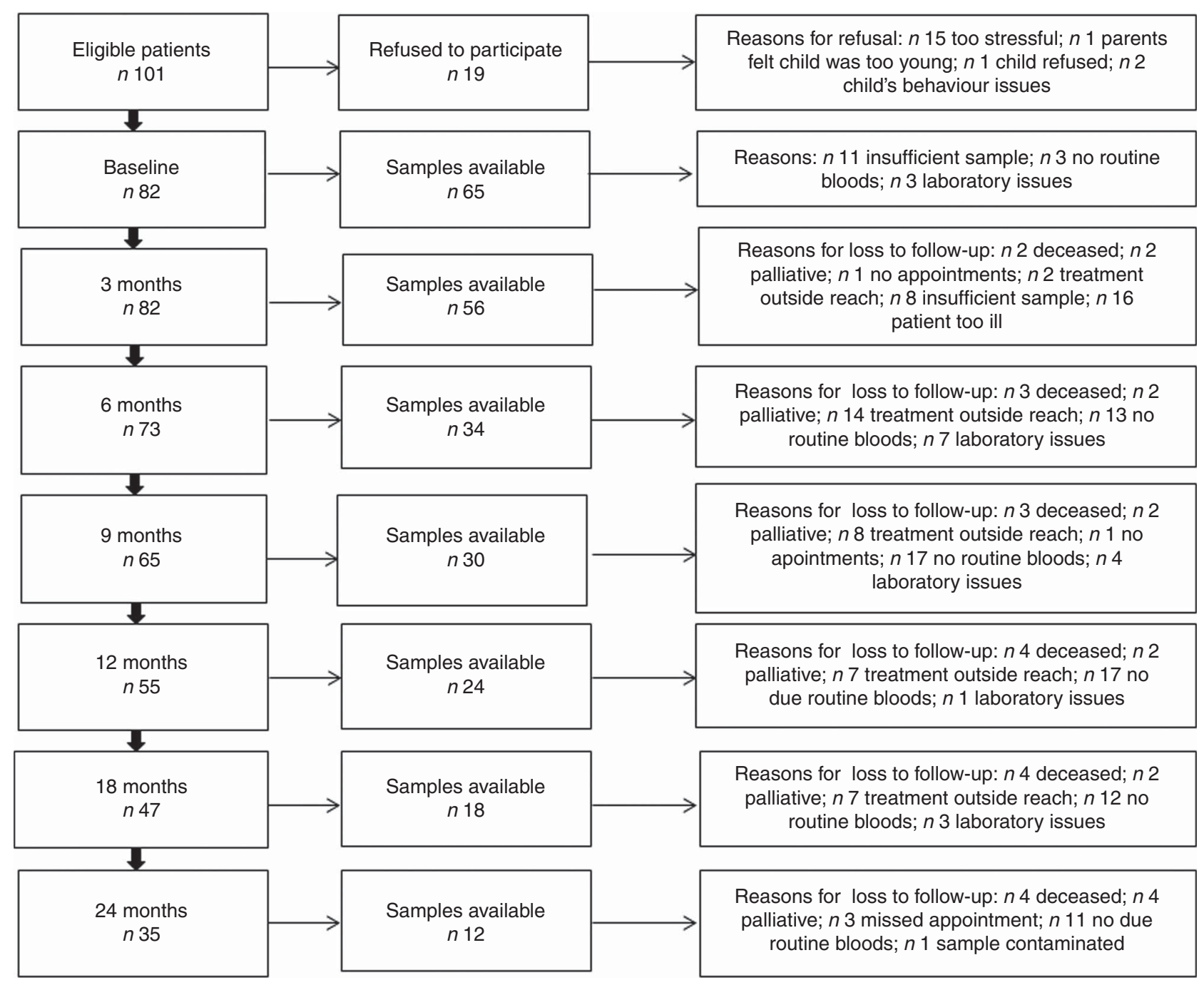

Fig. 1. Flow chart showing the sample size at different stages of the study period. 
Table 1. Characteristics of the paediatric cancer population and the healthy controls (Medians and interquartile ranges (IQR); numbers and percentages)

\begin{tabular}{|c|c|c|c|c|c|}
\hline \multirow[b]{2}{*}{ Baseline characteristics } & \multicolumn{2}{|c|}{ Paediatric cancer cohort } & \multicolumn{2}{|c|}{ Controls } & \multirow[b]{2}{*}{$P$} \\
\hline & Median & IQR & Median & IQR & \\
\hline Total sample $(n)$ & \multicolumn{2}{|c|}{82} & \multicolumn{2}{|c|}{35} & \\
\hline Age & 3.9 & $1.9-8.8$ & $6 \cdot 2$ & $4 \cdot 8-9 \cdot 1$ & $0.1^{*}$ \\
\hline BMI centile & 50 & $19 \cdot 0-84.5$ & $60 \cdot 5$ & $43 \cdot 7-89.5$ & $0.003^{*}$ \\
\hline \multirow[t]{2}{*}{ Plasma 25(OH)D } & $38 \cdot 0$ & $21 \cdot 0-61 \cdot 0$ & $37 \cdot 5$ & $23 \cdot 0-58 \cdot 0$ & $0.7^{\star}$ \\
\hline & $n$ & $\%$ & $n$ & $\%$ & \\
\hline Sex & & & & & $0.5 \dagger$ \\
\hline Male & 46 & $56 \cdot 1$ & 17 & $48 \cdot 6$ & \\
\hline Female & 36 & $43 \cdot 9$ & 18 & 51.4 & \\
\hline Ethnicity & & & & & $0.6 \dagger$ \\
\hline White & 80 & $97 \cdot 6$ & 33 & $94 \cdot 3$ & \\
\hline Non-white & 2 & $2 \cdot 4$ & 2 & $5 \cdot 7$ & \\
\hline SES & & & & & $0.06 \dagger$ \\
\hline I & 15 & $18 \cdot 3$ & 3 & 8.6 & \\
\hline II & 13 & $15 \cdot 8$ & 8 & 22.9 & \\
\hline III & 15 & $18 \cdot 3$ & 5 & $14 \cdot 3$ & \\
\hline IV & 24 & $29 \cdot 3$ & 5 & $14 \cdot 3$ & \\
\hline $\mathbf{V}$ & 15 & $18 \cdot 3$ & 14 & $40 \cdot 0$ & \\
\hline Haematological malignancies & 35 & 43 & - & - & \\
\hline ALL & 29 & 35 & & & \\
\hline AML & 3 & 4 & & & \\
\hline CML & 2 & 2 & & & \\
\hline $\mathrm{HLH}$ & 1 & 1 & & & \\
\hline Solid tumours & 39 & 47 & & & \\
\hline Lymphomas & 10 & 12 & & & \\
\hline Neuroblastoma & 6 & 7 & - & - & \\
\hline Retinoblastoma & 2 & 2 & - & - & \\
\hline Renal tumours & 6 & 7 & - & - & \\
\hline Hepatic tumours & 1 & 1 & - & - & \\
\hline Malignant bone tumours & 4 & 5 & - & - & \\
\hline Soft tissue sarcoma & 5 & 6 & - & - & \\
\hline Germ cell tumours & 1 & 1 & - & - & \\
\hline Malignant epithelial neoplasm & 4 & 5 & - & - & \\
\hline Other unspecified malignancy & 0 & 0 & - & - & \\
\hline Other associated diagnoses & 3 & 4 & - & - & \\
\hline $\mathrm{LCH}$ & 3 & 4 & & & \\
\hline Brain tumours-CNS tumours & 5 & 6 & & & \\
\hline
\end{tabular}

the non-synthesising (median 26.0, IQR 18.0-46.5) and synthesising periods (median 56.5, IQR 45.5-78.0). Baseline plasma 25(OH)D of the cancer cohort did not differ from the healthy controls $(P=0.7)$.

At baseline, prevalence of plasma $25(\mathrm{OH}) \mathrm{D}$ inadequacy was $64 \%(42 / 65)$ in cancer patients and 63\% (22/35) in healthy children. There was a higher prevalence of plasma $25(\mathrm{OH}) \mathrm{D}$ deficiency in paediatric cancer patients ( $n$ 19; 29\%) in comparison with healthy children ( $n 8 ; 22 \%$ ), but this was not statistically significant $\left(P=0 \cdot 2 ; \chi^{2}\right.$ test). In the cancer cohort, prevalence of plasma $25(\mathrm{OH}) \mathrm{D}$ inadequacy ranged between 33 and $50 \%$ throughout the study period (Fig. 3). Patients with solid tumours had the highest prevalence of $25(\mathrm{OH}) \mathrm{D}$ inadequacy $(34 \%)$ followed by haematological malignancies (26\%) at both baseline (Table 2) and at all time points (online Supplementary Table S1). At baseline, of thirty-two solid tumour patients 37.5\% ( $n$ 12) were deficient and $31.2 \%(n$ 10) were insufficient and of twenty-six haemalogical malignancy patients $19 \cdot 2 \%(n 5)$ were deficient and $46 \cdot 1 \%$ ( $n$ 12) were insufficient (Table 2 ).
Nutritional support was prescribed to $26 \%$ (21/82) of paediatric cancer patients at baseline, of which 14/82 (17\%) were on macronutrients (enteral \pm parenteral nutrition) and $7 / 82$ (8\%) were on both macronutrients (enteral \pm parenteral nutrition) and micronutrients. The median time between the start of nutritional support and baseline was 8 (IQR 0-23) d. In all, $80 \%(66 / 82)$ of cancer patients received vitamin $\mathrm{D}$ from one or more forms of nutritional support for several days or weeks during the study period. Of these, 39/82 received macronutrient supplementation providing 292 (IQR 128-332) IU/d, 48/82 (58\%) received both micronutrient and macronutrient supplementation providing 464 (IQR 440-664) IU/d and 21/82 (26\%) received macronutrient only and micronutrient ( \pm macronutrient) supplementation. The vitamin D intake from diet alone was 68 (IQR 24-76) IU/d and supplementation of vitamin D ranged from $400 \mathrm{IU} / \mathrm{d}$ to $20000 \mathrm{IU}$ single dose of vitamin D during the study period.

Paediatric cancer patients who were not supplemented had the lowest plasma 25(OH)D. The prevalence of plasma 25(OH)D 


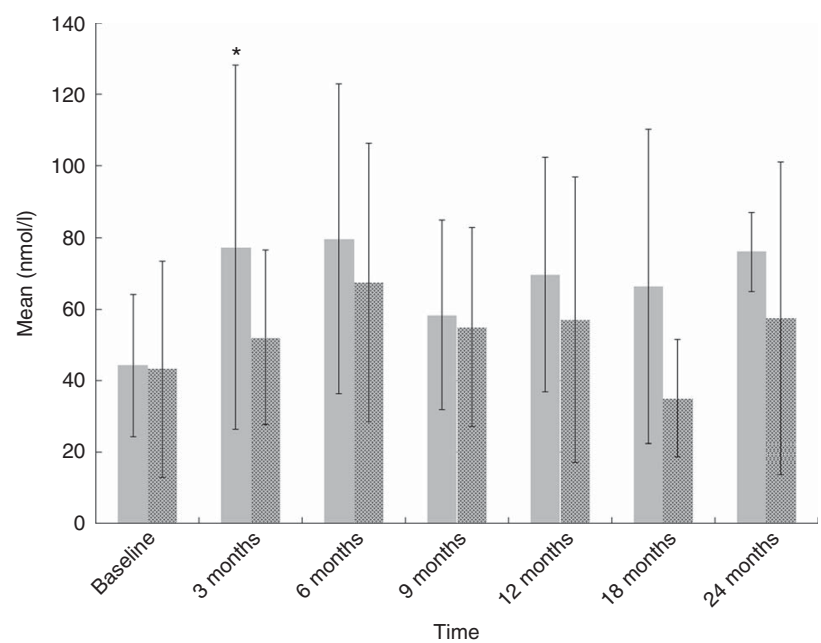

Fig. 2. Plasma 25-hydroxyvitamin $D(25(\mathrm{OH}) \mathrm{D})$ with data stratified according to seasonal variation. Values are means, with their standard deviations represented by vertical bars ( ${ }^{*} P<0.05$ ), independent $t$ test used to compare $25(\mathrm{OH}) \mathrm{D}$ concentration between synthesising (, 1 April-30 September) and non-

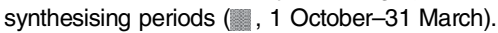

inadequacy stratified by nutritional support and stages of disease is presented in Table 3. This was highest in children who did not receive supplementation ranging from $32 \cdot 0$ (IQR 21.0-46.5) nmol/1 at 18 months to $45 \cdot 0$ (IQR $28 \cdot 0-64 \cdot 5) \mathrm{nmol} / 1$ at 24 months. In contrast, paediatric cancer patients supplemented with micronutrients ( \pm macronutrient) had the lowest prevalence of plasma $25(\mathrm{OH}) \mathrm{D}$ inadequacy and the highest plasma $25(\mathrm{OH}) \mathrm{D}$ at most stages ranging from 78.0 (IQR $49 \cdot 2-134 \cdot 5) \mathrm{nmol} / \mathrm{l}$ at 6 months to $82 \cdot 0$ (IQR $57 \cdot 0-128 \cdot 5) \mathrm{nmol} / \mathrm{l}$ at 12 months. This was followed by children supplemented with macronutrients only, which ranged from $43.0(29 \cdot 2-75 \cdot 7) \mathrm{nmol} / \mathrm{l}$ at baseline to $79 \cdot 0$ (IQR 49.0$93.0) \mathrm{nmol} / \mathrm{l}$ at 6 months. A considerable number of patients in the macronutrient subgroup had already received micronutrient supplementation. Of the seven patients who were on macronutrient support at 6 months, all of them had received micronutrient supplementation previously. Similarly, 2/5 (40\%) patients on macronutrient support at 12 months and 1/2 (50\%) patients at 18 months had received micronutrient supplementation in the previous follow-up. Moreover, micronutrient supplementation was significantly associated with a lower prevalence of plasma $25(\mathrm{OH}) \mathrm{D}$ inadequacy (Fisher's exact test; $P=0 \cdot 04$; relative risk $0.27 ; 95 \% \mathrm{CI} 0.04,1.8)$ at 6 months. Three patients reached plasma $25(\mathrm{OH}) \mathrm{D}$ concentration of $>175 \mathrm{nmol} / \mathrm{l}^{(17)}$ following a single high dose $(20000 \mathrm{IU} / \mathrm{d})$ of vitamin D.

Plasma 25(OH)D did not correlate with plasma $\mathrm{Ca}$, phosphate, $\mathrm{Mg}$ and PTH at any stage in the cancer cohort; however, PTH and plasma $25(\mathrm{OH}) \mathrm{D}$ concentration correlated in the healthy controls $(r 0 \cdot 6 ; P<0 \cdot 001)$.

\section{Factors contributing to 25-hydroxyvitamin D inadequacy concentration at baseline and at 3 and 6 months of treatment}

Age negatively correlated with plasma $25(\mathrm{OH}) \mathrm{D}$ concentration in paediatric cancer patients $(r-0.46 ; P<0.001)$, only at baseline, and in healthy children $(r-0.42 ; P<0.02)$, whereby older children 

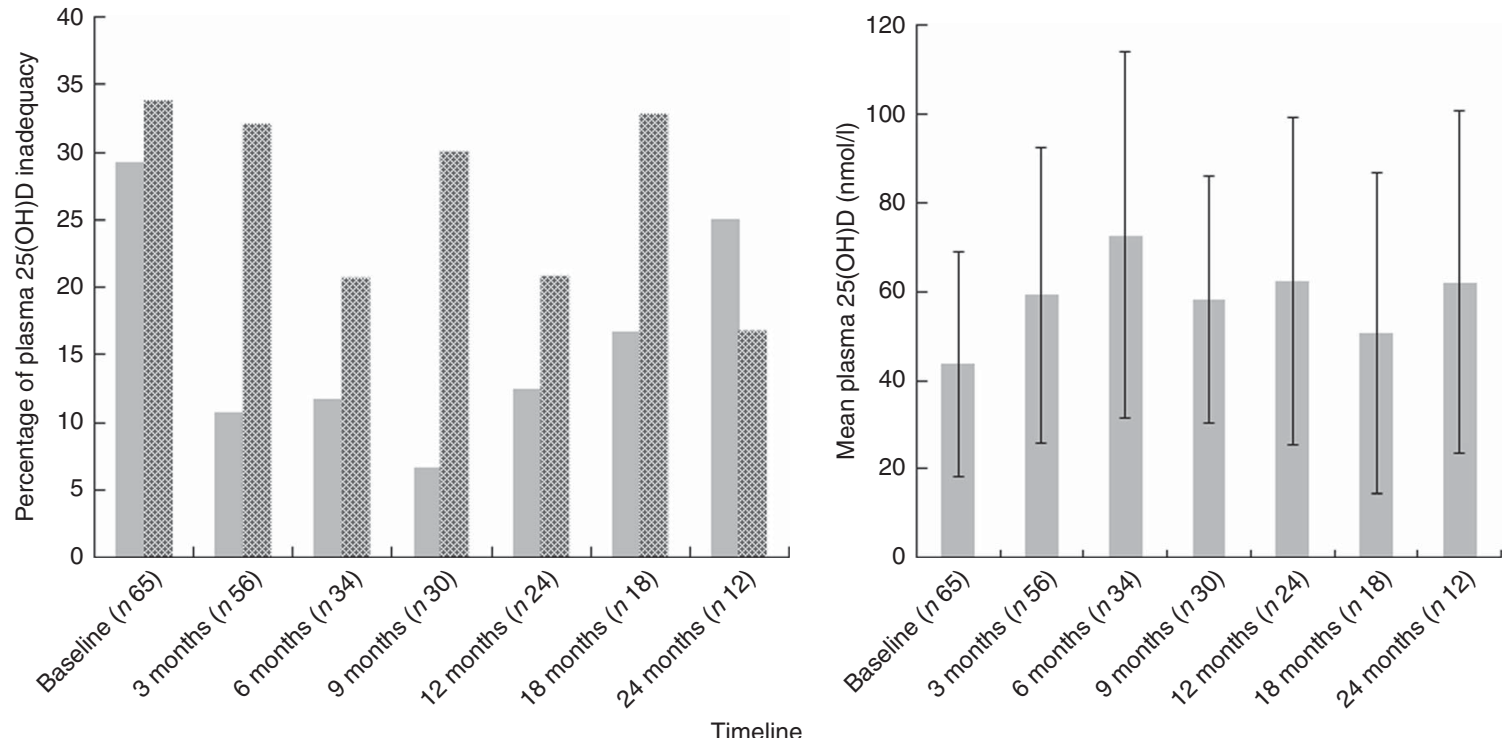

Fig. 3. Plasma 25-hydroxyvitamin $\mathrm{D}(25(\mathrm{OH}) \mathrm{D})$ concentration ( , deficiency $<25 \mathrm{nmol} / \mathrm{l}$, left) and prevalence of $25(\mathrm{OH}) \mathrm{D}$ deficiency and insufficiency $(\mathrm{i}$, insufficiency $25-50 \mathrm{nmol} / \mathrm{l}$, right) at different stages of the study period. Values are means, with their standard deviations represented by vertical bars (left).

Table 3. Prevalence of plasma 25-hydroxyvitamin $\mathrm{D}(25(\mathrm{OH}) \mathrm{D})$ inadequacy with data stratified by nutritional support and at different stages of the disease $\dagger$ (Numbers and percentages; medians and interquartile ranges (IQR))

\begin{tabular}{|c|c|c|c|c|c|c|c|c|c|c|c|c|}
\hline \multirow[b]{2}{*}{ Timeline } & \multirow[b]{2}{*}{ Nutritional support } & \multirow[b]{2}{*}{$n$} & \multicolumn{2}{|c|}{ Deficiency } & \multicolumn{2}{|c|}{ Insufficiency } & \multicolumn{2}{|c|}{ Sufficiency } & \multicolumn{2}{|c|}{ Optimal } & \multirow[b]{2}{*}{ Median } & \multirow[b]{2}{*}{ IQR } \\
\hline & & & $n$ & $\%$ & $n$ & $\%$ & $n$ & $\%$ & $n$ & $\%$ & & \\
\hline \multirow[t]{3}{*}{ Baseline ( $(n 65)$} & None & 44 & 16 & 25 & 15 & 23 & 11 & 17 & 2 & 3 & $34 \cdot 0$ & $20 \cdot 2-52 \cdot 7$ \\
\hline & Macronutrients & 14 & 2 & 3 & 6 & 9 & 3 & 5 & 3 & 5 & 43.0 & $29 \cdot 2-75 \cdot 7$ \\
\hline & Micronutrients \pm macronutrients & 7 & 1 & 1 & 1 & 1 & 3 & 5 & 2 & 3 & 71.0 & $41 \cdot 0-97 \cdot 0$ \\
\hline \multirow[t]{3}{*}{3 months ( $n$ 55) } & None & 25 & 4 & 7 & 11 & 20 & 6 & 11 & 4 & 7 & $45 \cdot 0$ & $32 \cdot 0-56 \cdot 0$ \\
\hline & Macronutrients & 9 & 1 & 2 & 1 & 2 & 4 & 7 & 3 & 5 & $67 \cdot 0$ & $48 \cdot 0-76.5$ \\
\hline & Micronutrients \pm macronutrients & 20 & 1 & 2 & 6 & 11 & 7 & 13 & 6 & 11 & 67.5 & $38 \cdot 0-87 \cdot 7$ \\
\hline \multirow[t]{3}{*}{6 months ( $n$ 34) } & None & 9 & 3 & 9 & 2 & 6 & 4 & 12 & 0 & 0 & $45 \cdot 0$ & $16 \cdot 5-68 \cdot 0$ \\
\hline & Macronutrients & 7 & 0 & 0 & 2 & 6 & 1 & 3 & 4 & 12 & 79.0 & $49 \cdot 0-93 \cdot 0$ \\
\hline & Micronutrients \pm macronutrients & 18 & 1 & 3 & 3 & 9 & 4 & 12 & 10 & 29 & $78 \cdot 0$ & $49 \cdot 2-134 \cdot 5$ \\
\hline \multirow[t]{3}{*}{9 months ( $n 30)$} & None & 16 & 1 & 3 & 7 & 23 & 6 & 20 & 2 & 7 & $45 \cdot 0$ & $31 \cdot 0-61 \cdot 0$ \\
\hline & Macronutrients & 8 & 1 & 3 & 2 & 7 & 2 & 7 & 3 & 10 & $59 \cdot 0$ & $35.5-84.25$ \\
\hline & Micronutrients \pm macronutrients & 6 & 0 & 0 & 0 & & 2 & 7 & 4 & 13 & $77 \cdot 5$ & $66 \cdot 5-101 \cdot 0$ \\
\hline \multirow{3}{*}{12 months ( $n$ 24) } & None & 11 & 3 & 12 & 4 & 17 & 1 & 4 & 3 & 12 & $36 \cdot 0$ & $24.5-79.0$ \\
\hline & Macronutrients & 5 & 0 & 0 & 1 & 4 & 4 & 17 & 0 & 0 & 63.0 & $51 \cdot 0-63.0$ \\
\hline & Micronutrients \pm macronutrients & 8 & 0 & 0 & 0 & 0 & 5 & 21 & 3 & 12 & $82 \cdot 0$ & $57 \cdot 0-128 \cdot 5$ \\
\hline \multirow[t]{3}{*}{18 months ( $n$ 18) } & None & 12 & 3 & 17 & 7 & 39 & 2 & 11 & 0 & 0 & $32 \cdot 0$ & $21-46 \cdot 5$ \\
\hline & Macronutrients & 2 & 0 & 0 & 0 & 0 & 1 & 6 & 1 & 6 & 67.5 & $56 \cdot 0$ \\
\hline & Micronutrients \pm macronutrients & 3 & 0 & 0 & 0 & 0 & 3 & 17 & 0 & 0 & $64 \cdot 0$ & $42 \cdot 7-134 \cdot 0$ \\
\hline \multirow[t]{3}{*}{24 months ( $n$ 12) } & None & 5 & 1 & 8 & 2 & 17 & 2 & 17 & 0 & 0 & $45 \cdot 0$ & $28 \cdot 0-64.5$ \\
\hline & Macronutrients & 0 & 0 & 0 & 0 & 0 & 0 & 0 & 0 & 0 & & \\
\hline & Micronutrients \pm macronutrients & 7 & 2 & 17 & 1 & 8 & 0 & 0 & 4 & 33 & $67 \cdot 0$ & $23 \cdot 7-106 \cdot 2$ \\
\hline
\end{tabular}

OAD, other associated diagnoses.

† 25(OH)D reference ranges: deficiency $<25 \mathrm{nmol} / \mathrm{l}$, insufficiency $25-50 \mathrm{nmol} / \mathrm{l}$, sufficiency $51-75 \mathrm{nmol} / \mathrm{l}$, optimal $>75 \mathrm{nmol} / \mathrm{l}, 25(\mathrm{OH}) \mathrm{D}$ inadequacy $(<50 \mathrm{nmol} / \mathrm{l})$.

had lower plasma 25(OH)D concentration. Although BMI centile was not significantly correlated with plasma $25(\mathrm{OH}) \mathrm{D}$ concentration in the paediatric cancer cohort at baseline $(r-0 \cdot 2 ; P=0 \cdot 08)$, 3 months $(r-0.2 ; P=0.2)$ and 6 months $(r-0.2 ; P=0.3)$, and in the healthy controls $(r-0 \cdot 3 ; P=0 \cdot 3)$, overnourished paediatric cancer patients were more likely to have higher prevalence of plasma 25(OH)D inadequacy $\left(\chi^{2}\right.$ test (8.3); df (1); $P=0.005$; relative risk $3 \cdot 1 ; 95 \% \mathrm{CI} 1 \cdot 4,14 \cdot 0)$ at 3 months than healthy and undernourished children with cancer, regardless of whether the patients were on nutritional supplementation. Non-supplemented children were more likely to have inadequate plasma $25(\mathrm{OH}) \mathrm{D}$ concentration (relative risk $4.3 ; 95 \%$ CI 1.1, 4.7) at 6 months (Fisher's exact test; $P=0.04$ ) compared with those supplemented with micronutrients.

None of the following categorical variables were significantly associated with plasma 25(OH)D status and paediatric cancer patients at any stage: treatment risk, diagnostic criteria, ethnicity and sex 


\section{Discussion}

This is the first study investigating plasma $25(\mathrm{OH}) \mathrm{D}$ concentration at diagnosis and during treatment in paediatric cancer patients from Scotland. Our results show a high prevalence of plasma $25(\mathrm{OH}) \mathrm{D}$ inadequacy during the study period. Plasma $25(\mathrm{OH}) \mathrm{D}$ concentration in paediatric cancer patients and age-matched healthy controls were similar; however, our paediatric cancer cohort showed no seasonal variation. Children diagnosed with solid tumours exhibited the lowest plasma 25(OH)D concentration and the only effective method to achieve optimal plasma $25(\mathrm{OH}) \mathrm{D}$ concentration was by supplementing with vitamin D. Only three factors, and each at 1 time point only, contributed to plasma 25(OH)D inadequacy: older age was the only factor at baseline, overnutrition at 3 months and not being supplemented at 6 months during treatment.

\section{Prevalence of plasma 25-hydroxyvitamin D}

In contrast to North England ${ }^{(22)}$ but in agreement with a recent Scottish small study ${ }^{(23)}$, our study shows that plasma $25(\mathrm{OH}) \mathrm{D}$ concentration in newly diagnosed paediatric cancer patients and healthy children were comparable, suggesting that patients from Scotland are not at a higher risk of plasma 25(OH)D inadequacy than healthy children at diagnosis. However, these concentrations are lower than those reported in paediatric cancer patients from Europe ${ }^{(6)}$. Of note, $11 \%$ of paediatric cancer patients were on vitamin D supplementation at baseline, which may have contributed to higher plasma 25(OH)D concentration at this stage. In addition, there was a higher representation of winter samples in the healthy controls than the paediatric cancer cohort (30v. 43\%), which might have contributed to the unexpectedly higher prevalence of vitamin D inadequacy in the healthy controls.

Optimal plasma 25(OH)D in children is essential to allow optimal growth, Ca homoeostasis and skeletal development ${ }^{(3)}$. Children treated for cancer may have impaired growth velocity during treatment ${ }^{(24)}$, which can also be exacerbated by vitamin D inadequacy. Current UK guidelines on vitamin D are aimed at healthy children and stipulate that children under 5 years of age should be supplemented with $7 \cdot 5-10 \mu \mathrm{g} / \mathrm{d}(300-400 \mathrm{IU})$ of vitamin $\mathrm{D}^{(2)}$. We have clearly established that most cancer patients who were not supplemented were either deficient or insufficient, or eventually became deficient, as shown by the high prevalence of plasma 25(OH)D inadequacy (33-50\%). Furthermore, macronutrient supplementation alone prevented plasma $25(\mathrm{OH}) \mathrm{D}$ inadequacy, but patients rarely reached optimal concentration, suggesting that macronutrient supplementation, which is fortified with vitamin D, does not meet the requirements for vitamin $\mathrm{D}$ in this population. Finally, vitamin D supplementation taken in the form of multivitamins or as therapeutic supplementation was essential to achieve optimal 25(OH)D concentration in all paediatric cancer patients. Remarkably, we found that older children were at a higher risk of plasma $25(\mathrm{OH}) \mathrm{D}$ inadequacy at baseline and therefore would also require supplementation, which is not stipulated in the $\mathrm{RCPCH}$ guidelines ${ }^{(2)}$. However, it is important to note that three patients on single high-dose (20000 IU) vitamin D supplementation reached $25(\mathrm{OH}) \mathrm{D}>175 \mathrm{nmol} / \mathrm{l}$ concentration $^{(17)}$.
Therefore, we recommend vitamin D supplementation for all paediatric cancer patients, but emphasise the need for close monitoring to avoid potential toxicity.

Unlike healthy children, our paediatric cancer cohort did not show any seasonal variation in plasma $25(\mathrm{OH}) \mathrm{D}$ concentration. These findings are supported by a study performed in survivors of childhood cancer from the USA (latitude $\left.34^{\circ} \mathrm{N}\right)^{(25)}$ but contrasts with two studies ${ }^{(22,26)}$ : one performed in North England (latitude $54.9^{\circ} \mathrm{N}$ ) during and after therapy ${ }^{(22)}$ and the other performed in Israel (latitude $31^{\circ} \mathrm{N}$ ) in paediatric cancer patients during therapy ${ }^{(26)}$. Therefore, we hypothesise that Scottish paediatric cancer patients are not exposed to enough sunlight during the summer months, probably becase of the multiple treatment side effects ${ }^{(24,25)}$, and that diet alone is insufficient to replenish plasma $25(\mathrm{OH}) \mathrm{D}$ stores.

Stratification of the data by diagnosis revealed results consistent with a recent systematic review ${ }^{(6)}$ and a large study ( $n$ 2198) performed in the adult oncology population from USA. Patients diagnosed with solid tumours had prevalence of plasma $25(\mathrm{OH}) \mathrm{D}$ inadequacy of 71 and $75 \%$, respectively; our study showed that children diagnosed with solid tumours exhibited the highest prevalence of plasma $25(\mathrm{OH}) \mathrm{D}$ inadequacy (69\%; deficiency $37.5 \%$ and insufficiency $31.2 \%$ ) at diagnosis. However, our study also showed high prevalence of plasma $25(\mathrm{OH}) \mathrm{D}$ inadequacy in the haematological malignancy group (65\%; deficiency $19 \cdot 2 \%$ and insufficiency $46 \cdot 1 \%$ ) at diagnosis, which contrasts with findings from elsewhere ${ }^{(6,25)}$. Although others have reported similar prevalence of vitamin D inadequacy in Canadian children diagnosed with haematological malignancies ${ }^{(27,28)}$, the measured vitamin $\mathrm{D}$ was 1,25 -dihydroxyvitamin $\mathrm{D}(1,25(\mathrm{OH}) 2 \mathrm{D})$, which is not equivalent to plasma 25(OH)D. Despite supplementation with macronutrients and micronutrients, prevalence of $25(\mathrm{OH}) \mathrm{D}$ inadequacy remained high during treatment for solid tumours and haematological malignancies, highlighting the need for more rigorous monitoring at all stages.

In line with recent evidence ${ }^{(6,22)}$, our study found a relationship between PTH and plasma 25(OH)D in healthy controls, but not in paediatric cancer patients. Although in health PTH measured alongside plasma $25(\mathrm{OH}) \mathrm{D}$ is considered the most sensitive physiological measure of plasma $25(\mathrm{OH}) \mathrm{D}$ status and bone homoeostasis ${ }^{(29)}$, our study suggests that there might be other factors influencing their relationship. We were unable to investigate this because of the relatively small sample; however, it has been attributed to the type of cancer and the different treatments, including chemotherapy and corticosteroids, which can lead to nephrotoxicity and hepatotoxicity, in turn interfering with the 25(OH)D, 1,25(OH)2D and PTH metabolism ${ }^{(10,30)}$. Furthermore, a stronger relationship between plasma PTH and 25(OH)D develops with age ${ }^{(31)}$, which might have affected our results, as the controls were slightly older.

\section{Factors contributing to reduced plasma 25-hydroxyvitamin D concentration at baseline and at 3 and 6 months}

Consistent with a meta-analysis ${ }^{(6)}$, older age was associated with reduced plasma $25(\mathrm{OH}) \mathrm{D}$ concentration in paediatric cancer patients at baseline. This association was also found in 
our healthy controls, in line with a study performed in healthy children from the USA ${ }^{(32)}$, which could reflect the widespread issue of vitamin D. Teenagers tend to eat less vitamin-D-rich foods, especially fortified foods, and spend less time playing outdoors than younger children ${ }^{(33)}$. In addition, the high levels of vitamin D inadequacy during treatment could have been attributed to the fact that patients were supplemented with a very low dose of vitamin D (440-664 IU). A higher dose of $600 \mathrm{IU}$ is recommended for all paediatric patients (including infants), whereas therapeutic doses are age dependent and all doses are over $1000 \mathrm{IU} / \mathrm{d}^{(3,17)}$. Alongside infancy, puberty is accompanied by a rapid period of growth, and appropriate plasma $25(\mathrm{OH}) \mathrm{D}$ concentration is essential to allow for optimal growth $^{(34)}$; thus, this population should be targeted and appropriate doses should be prescribed to all patients.

In contrast with other studies investigating factors contributing to plasma $25(\mathrm{OH}) \mathrm{D}$ inadequacy in paediatric cancer patients ${ }^{(23,26)}$, our results showed that ${ }^{(7)}$ like healthy individuals, overnourished children maybe more likely to have plasma 25(OH)D inadequacy following 3 months of treatment, and this was regardless of nutritional support. An inverse relationship between high BMI and plasma $25(\mathrm{OH}) \mathrm{D}$ in the healthy population is well established ${ }^{(7)}$, which has been attributed to a reduction in plasma $25(\mathrm{OH}) \mathrm{D}$ availability due to the sequestration of vitamin $\mathrm{D}$ by adipose tissue ${ }^{(35)}$. Overweight children require higher doses of chemotherapy and glucocorticoids than normal-weight or undernourished children. In addition, cancer treatments tend to be most intense during the first 3-6 months post diagnosis. Chemotherapy agents commonly used in cancer treatment can cause hepatotoxicity and nephrotoxicity and thus inhibit the activation of vitamin $\mathrm{D}^{(27)}$, whereas glucocorticoids stimulate vitamin D catabolism and can increase the risk of vitamin D deficiency ${ }^{(27)}$. Therefore, higher doses of chemotherapy agents and glucocorticoids may explain this association between overnourished patients and lower $25(\mathrm{OH}) \mathrm{D}$ concentration

\section{Limitations of the study and future research}

The reduced sample size at later stages of the study precluded considering factors associated with plasma 25(OH)D at later stages of treatment. Some cancer patients were already on nutritional support at baseline, which could potentially have affected plasma $25(\mathrm{OH}) \mathrm{D}$ concentration. It should be noted that although age did not statistically differ between the controls and the cancer cohort, the controls were slightly older. In addition, the higher proportion of samples obtained from the nonsynthesising period in the controls may have distorted the high plasma $25(\mathrm{OH}) \mathrm{D}$ inadequacy reported. Finally, there were only two non-Caucasian patients (dark skin) in both groups, which could explain why lower plasma $25(\mathrm{OH}) \mathrm{D}$ concentration was not associated with ethnicity. Future research should include large multicentre epidemiological studies that are better able to identify factors contributing to plasma $25(\mathrm{OH}) \mathrm{D}$ inadequacy in the different types of cancer during treatment, as well as randomised controlled trials in which the effects of vitamin D supplementation on clinical outcome, particularly bone mass density, are warranted.

\section{Conclusion}

We have highlighted that Scottish paediatric cancer patients have a high prevalence of plasma $25(\mathrm{OH}) \mathrm{D}$ inadequacy at diagnosis and during treatment and that older age, not being supplemented and possibly being overnourished potentially contribute to inadequacy. Importantly, we recommend vitamin D supplementation to all paediatric cancer patients given that macronutrient supplementation alone prevented further $25(\mathrm{OH}) \mathrm{D}$ inadequacy, but rarely produced optimal concentration, and high longitudinal inadequacy rates continued throughout the study.

\section{Acknowledgements}

The authors thank Prof. Hamish Wallace, Prof. Angela Thomas, Dr Angela Edgar, Lindsay Archibald, Alison Gillies and Elaine Lawrie for their valuable input to the study, and Kerry White for ongoing support. The authors also wish to express their most sincere appreciation to the parents and children who took the time to participate in the research project.

This study was funded by the following funding bodies: Fergus Maclay Leukaemia Trust (a registered Scottish charity), Queen Margaret University, Cancer and Leukaemia Fund (Royal Hospital for Sick Children) and the GI-Nutrition Research fund of Child Life and Health, University of Edinburgh. The controls were funded by the Roald Dahl Marvellous Children's Charity and the Burdett Trust to carry out the study on vitamin D in children with epilepsy - 'Bone and brains'.

R. R. I. designed the study, collected the data from the paediatric cancer cohort, analysed the data, drafted the manuscripts and provided final approval of the manuscript; I. P. collected the data from the paediatric cancer cohort, and provided critical feedback and final approval of the manuscript; I. D. supervised the study, and provided critical feedback and final approval of the manuscript; J. M. supervised the study, and provided critical feedback and final approval of the manuscript; C. B. collected the data from the control cohort, and provided critical feedback and final approval; R. C. supervised the data collection from the controls, and provided critical feedback and final approval of the manuscript; M. B. supervised the study and data collection from the cohort, and provided critical feedback and final approval of the manuscript; D. W. designed, coordinated and supervised the study, and provided critical feedback and final approval of the manuscript.

The authors have no conflicts of interest relevant to this article to disclose.

\section{Supplementary material}

For supplementary material/s referred to in this article, please visit https://doi.org/10.1017/S0007114516004074

\section{References}

1. Ahmed SF, Franey C, McDevitt H, et al. (2011) Recent trends and clinical features of childhood vitamin D deficiency presenting to a children's hospital in Glasgow. Arch Dis Child 96, 694-696.

2. Royal College of Paediatrics and Child Health (RCPCH) (2013) Guide for vitamin D in childhood. http://www.rcpch.ac.uk/ vitamin-d (accessed January 2014). 
3. Holick MF, Binkley NC, Bischoff-Ferrari H, et al. (2011) Evaluation, treatment, and prevention of vitamin D deficiency: an Endocrine Society clinical practice guideline. J Clin Endocrinol Metab 96, 1911-1930.

4. Pramyothin P \& Holick MF (2012) Vitamin D supplementation: guidelines and evidence for subclinical deficiency. Curr Opin Gastroenterol 28, 139-150.

5. Choudhary A, Chou J, Heller G, et al. (2013) Prevalence of vitamin D insufficiency in survivors of childhood cancer. Pediatr Blood Cancer 60, 1237-1239.

6. Revuelta Iniesta R, Rush R, Paciarotti I, et al. (2015) Systematic review and meta-analysis: prevalence and possible causes of vitamin D deficiency and insufficiency in pediatric cancer patients. Clin Nutr 35, 95-108.

7. Holick MF (2006) High prevalence of vitamin D inadequacy and implications for health. Mayo Clin Proc 81, 353-373.

8. Public Health England (2007) Update on Vitamin D: Position Statement by the Scientific Advisory Committee on Nutrition. London: TSO.

9. Oeffinger KC, Mertens AC, Sklar CA, et al. (2006) Chronic health conditions in adult survivors of childhood cancer. N Engl J Med 355, 1572-1582.

10. Zhou C, Assem M, Tay JC, et al. (2006) Steroid and xenobiotic receptor and vitamin D receptor crosstalk mediates CYP24 expression and drug-induced osteomalacia. J Clin Invest 116, 1703-1712.

11. Herbst RS, Bajorin DF, Bleiberg H, et al. (2006) Clinical Cancer Advances 2005: major research advances in cancer treatment, prevention, and screening - a report from the American Society of Clinical Oncology. J Clin Oncol 24, 190-205.

12. Oeffinger KC \& Hudson MM (2004) Long-term complications following childhood and adolescent cancer: foundations for providing risk-based health care for survivors. CA Cancer J Clin 54, 208-236.

13. Wallace WHB, Thompson L \& Anderson RA (2013) Long term follow-up of survivors of childhood cancer: summary of updated SIGN guidance. BMJ 346, f1190.

14. Steliarova-Foucher E, Stiller C, Lacour B, et al. (2005) International Classification of Childhood Cancer, third edition. Cancer 103, $1457-1467$.

15. Kazak AE, Hocking MC, Ittenbach RF, et al. (2012) A revision of the intensity of treatment rating scale: classifying the intensity of pediatric cancer treatment. Pediatr Blood Cancer 59, 96-99.

16. The Scottish Government (2012) Scottish Index of Multiple Deprivation. http://www.scotland.gov.uk/Topics/Statistics/ SIMD/SIMDPostcodeLookup (accessed March 2012).

17. Royal Hospital for Sick Children (2014) Edinburgh Clinical Chemistry Laboratory Handbook. Edinburgh: Royal Hospital for Sick Children.

18. Cole TJ, Freeman JV \& Preece MA (1995) Body mass index reference curves for the UK, 1990. Arch Dis Child 73, 25-29.
19. Reilly JJ, Montgomery C, Jackson D, et al. (2001) Energy intake by multiple pass $24 \mathrm{~h}$ recall and total energy expenditure: a comparison in a representative sample of 3-4-year-olds. Br J Nutr 86, 601-605.

20. Wise A (2005) Wind diets. Robert Gordon University.

21. Vandenbroucke JP, von Elm E, Altman DG, et al. (2014) Strengthening the Reporting of Observational Studies in Epidemiology (STROBE): explanation and elaboration. Int J Surg 12, 1500-1524.

22. Sinha A, Avery P, Turner S, et al. (2011) Vitamin D status in paediatric patients with cancer. Pediatr Blood Cancer 57, 594-598.

23. Paciarotti I, Revuelta Iniesta R, McKenzie JM, et al. (2015) Low plasma vitamin D (25-hydroxycholecalciferol) in children and adolescents diagnosed with cancer: a case-control study. EC Nutr 3, 513-520.

24. Revuelta Iniesta R, Paciarotti I, Brougham MFH, et al. (2015) Effects of pediatric cancer and its treatment on nutritional status: a systematic review. Nutr Rev 73, 276-295.

25. Sala A, Pencharz P \& Barr RD (2004) Children, cancer, and nutrition - a dynamic triangle in review. Cancer 100, 677-687.

26. Modan-Moses D, Pinhas-Hamiel O, Munitz-Shenkar D, et al. (2012) Vitamin D status in pediatric patients with a history of malignancy. Pediatr Res 72, 620-624.

27. Atkinson SA, Halton JM, Bradley C, et al. (1998) Bone and mineral abnormalities in childhood acute lymphoblastic leukemia: influence of disease, drugs and nutrition. Int J Cancer Suppl 11, 35-39.

28. Halton JM, Atkinson SA, Fraher L, et al. (1996) Altered mineral metabolism and bone mass in children during treatment for acute lymphoblastic leukemia. J Bone Miner Res 11, 1774-1783.

29. Holick MF (2009) Vitamin D status: measurement, interpretation, and clinical application. Ann Epidemiol 19, 73-78.

30. Atkinson SA (2008) Vitamin D status and bone biomarkers in childhood cancer. Pediatr Blood Cancer 486, Suppl. 2, 479-482; discussion.

31. Greer FR (2009) Defining vitamin D deficiency in children: beyond $25-\mathrm{OH}$ vitamin $\mathrm{D}$ serum concentrations. Pediatrics 124, 1471-1473.

32. Kumar J, Muntner P, Kaskel FJ, et al. (2009) Prevalence and associations of 25-hydroxyvitamin D deficiency in US children: NHANES 2001-2004. Pediatrics 124, e362-e370.

33. Rosen GP, Beebe KL \& Shaibi GQ (2013) Vitamin D levels differ by cancer diagnosis and decline over time in survivors of childhood cancer. Pediatr Blood Cancer 60, 949-952.

34. Tanner J (1990) Physical Growth from Conception to Maturity. Cambridge, MA: Harvard University Press.

35. Wortsman J, Matsuoka LY, Chen TC, et al. (2000) Decreased bioavailability of vitamin D in obesity. Am J Clin Nutr $\mathbf{7 2}$, 690-693. 